\title{
The Constitution of Social Practices
}

\section{kevin mcmillan}

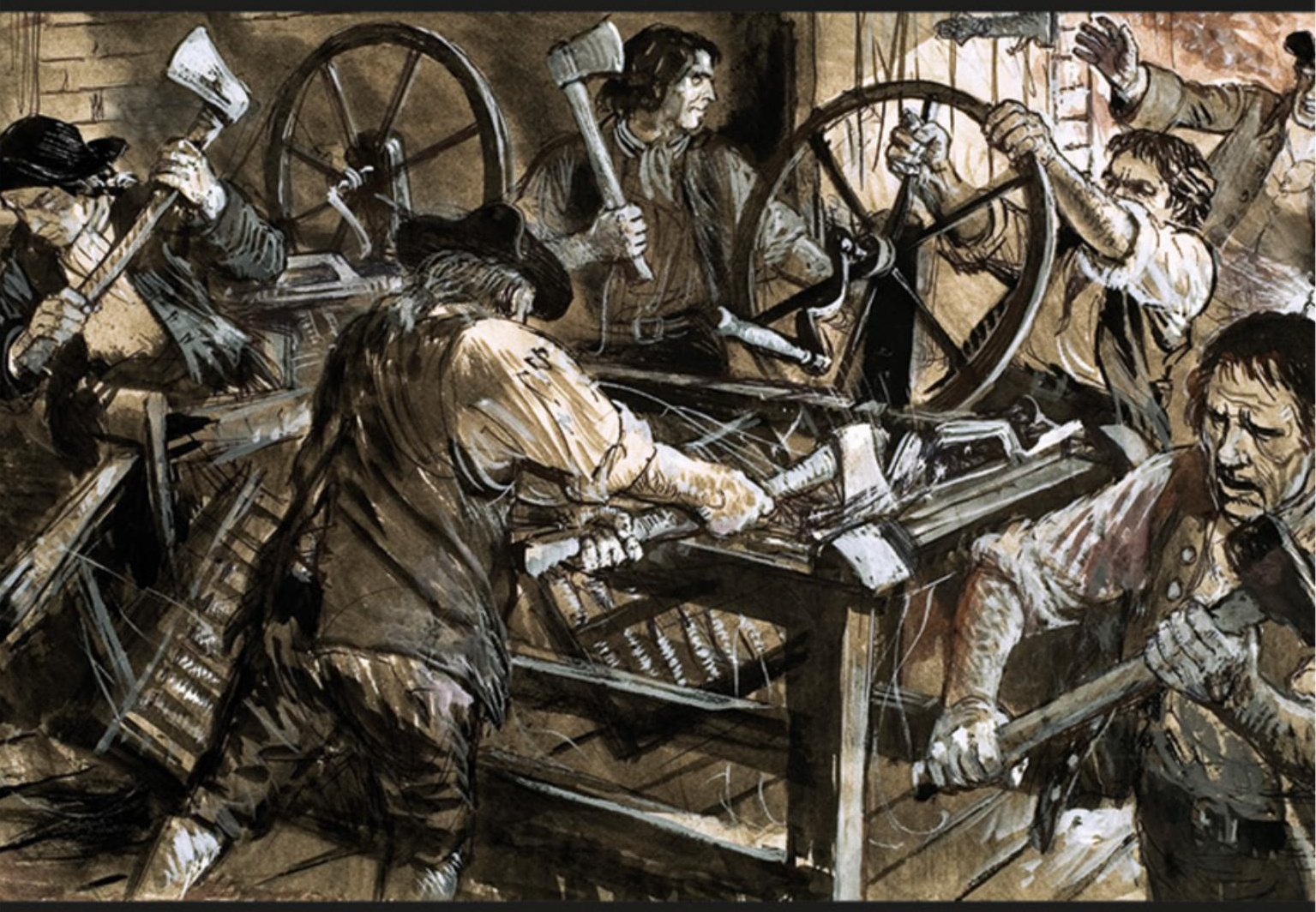




\section{The Constitution of Social Practices}

Practices - specific, recurrent types of human action and activity - are perhaps the most fundamental "building blocks" of social reality. This book argues that the detailed empirical study of practices is essential to effective social-scientific inquiry. It develops a philosophical infrastructure for understanding human practices, and argues that practice theory should be the analytical centrepiece of social theory and the philosophy of the social sciences.

What would social scientists' research look like if they took these insights seriously? To answer this question, the book offers an analytical framework to guide empirical research on practices in different times and places. The author explores how practices can be identified, characterised and explained, how they function in concrete contexts and how they might change over time and space.

The Constitution of Social Practices lies at the intersection of philosophy, social theory, cultural theory and the social sciences. It is essential reading for scholars in social theory and the philosophy of social science, as well as the broad range of researchers and students across the social sciences and humanities whose work stands to benefit from serious consideration of practices.

Kevin McMillan is Associate Professor in the School of Political Studies at the University of Ottawa, Canada. 


\title{
Philosophy and Method in the Social Sciences
}

\author{
Series Editor
}

Phil Hutchinson, Manchester Metropolitan University, UK

\begin{abstract}
Engaging with the recent resurgence of interest in methodological and philosophical issues in the human and social sciences, this series provides an outlet for work that demonstrates both the intellectual import of philosophical and methodological debates within the social sciences and their direct relevance to questions of politics, ethics or policy. Philosophy and Method in the Social Sciences welcomes work from sociologists, geographers, philosophers, anthropologists, criminologists and political scientists with broad interest across academic disciplines, that scrutinises contemporary perspectives within the human and social sciences and explores their import for today's social questions.

https://www.routledge.com/Philosophy-and-Method-in-the-Social-Sciences/ book-series/ASHSER1373
\end{abstract}

\section{Titles in this series}

\section{Wittgenstein among the Sciences}

Wittgensteinian Investigations into the 'Scientific Method'

Rupert Read, Edited by Simon Summers

(Ashgate, 2012)

\section{Clarity and Confusion in Social Theory}

Taking Concepts Seriously

Leonidas Tsilipakos

(Ashgate, 2015)

\section{Evolution, Human Behaviour and Morality}

The Legacy of Westermarck

Edited by Olli Lagerspetz, with Jan Antfolk, Ylva Gustafsson and Camilla

Kronqvist

\section{The Constitution of Social Practices}

Kevin McMillan 


\title{
The Constitution of Social Practices
}

Kevin McMillan

\author{
Routledge \\ 䎡 Taylor \& Francis Group \\ LONDON AND NEW YORK
}


First published 2018

by Routledge

2 Park Square, Milton Park, Abingdon, Oxon OX14 4RN

and by Routledge

711 Third Avenue, New York, NY 10017

Routledge is an imprint of the Taylor \& Francis Group, an informa business

(C) 2018 Kevin McMillan

The right of Kevin McMillan to be identified as author of this work has been asserted by him in accordance with sections 77 and 78 of the Copyright, Designs and Patents Act 1988.

All rights reserved. No part of this book may be reprinted or reproduced or utilised in any form or by any electronic, mechanical, or other means, now known or hereafter invented, including photocopying and recording, or in any information storage or retrieval system, without permission in writing from the publishers.

Trademark notice: Product or corporate names may be trademarks or registered trademarks, and are used only for identification and explanation without intent to infringe.

British Library Cataloguing in Publication Data

A catalogue record for this book is available from the British Library

Library of Congress Cataloging in Publication Data

Names: McMillan, Kevin, author.

Title: The constitution of social practices / Kevin McMillan.

Description: 1st Edition. | New York : Routledge, 2018. | Series: Philosophy and method in the social sciences | Includes bibliographical references and index.

Identifiers: LCCN 2017019485| ISBN 9781138894617 (hardback) | ISBN 9781315179902 (ebook)

Subjects: LCSH: Social sciences-Philosophy.

Classification: LCC H61 .M4823 2018 | DDC 300.1—de23

LC record available at https://lccn.loc.gov/2017019485

ISBN: 978-1-138-89461-7 (hbk)

ISBN: 978-1-315-17990-2 (ebk)

Typeset in Times New Roman

by Swales \& Willis Ltd, Exeter, Devon, UK 
For Jas, Soren \& Josha 
$\because$ Taylor \& Francis

Taylor \& Francis Group

http://taylorandfrancis.com 


\section{Contents}

List of figures $\quad$ ix

Introduction 1

1 A "cultural" approach to social science 2

2 Practice theory today 4

3 Core ontological commitments 8

4 Sketch of the argument 10

5 Of philosophy and social science 14

1 What are practices?

1 Actions under a description 22

2 Looping effects 28

3 Historical constitution 30

2 Knowledge

1 Knowledgeable practices 36

2 Conceptualising knowledge 40

3 Retroactive redescription

1 The validity of retroactive redescription 64

2 The effects of retroactive redescription 68

3 Functional concepts and typological classification 73

4 What is at stake? 78

4 Identification and context

1 Identifying practices "in all their specificity" 85

2 Relations and relational properties 88

3 Criteria of identification 92 
viii Contents

5 Specificity and generalisation

1 Functions 103

2 Implications for generalisation, explanation and description 111

3 Patchwork holism 118

6 Possibility and capacities

1 Possibility 123

2 Capacities 131

7 Constitutive relations and constitutive theory

1 Constitutive theory 145

2 Constitutive relations 146

3 Stability and change 152

Conclusion

1 Culture and action in the social sciences 158

2 Some benefits of studying practices 162

Works cited

Index 


\section{Figures}

2.1 Are relations among concepts "internal relations"? 44

2.2 "Foucault's fork" $\quad 50$

2.3 The sincerity of discourse and the psychoanalytic stance 53

$\begin{array}{lll}3.1 & \text { The significance of actors' categories } & 63\end{array}$

3.2 The difference ("explicit") concepts make 65

$\begin{array}{lr}6.1 \text { Observing intentional actions } & 133\end{array}$

8.1 "Individualism" and social explanation 166 
$\because$ Taylor \& Francis

Taylor \& Francis Group

http://taylorandfrancis.com 


\section{Introduction}

Thinkers once spoke of 'structures', 'systems', 'meaning', 'life world', 'events' and 'actions' when naming the primary generic social thing. Today, many theorists would accord 'practices' a comparable honour.

Theodore Schatzki, "Practice Theory"

So begins the introduction to a much-cited volume advocating a "practice turn" in contemporary social theory (Schatzki, Knorr Cetina and von Savigny 2001: 1). I think these anonymous theorists are on the right track. Human practices are a fundamental constituent - arguably "the" fundamental constituent - of social reality. This book attempts to develop the implications of this observation for the social sciences. It therefore seeks to demonstrate the considerable potential fertility both theoretical and empirical - of a research programme centred on historical practices. It suggests that the empirical social sciences and humanities would reap considerable rewards from paying more systematic attention to practices as an object of analysis.

In some quarters, a claim like this is likely to meet something of a paradoxical response: some are liable to see it as rather obscure, others as utterly trite. This book seeks to show that it is neither. For the puzzled reader, it proposes an original, systematic framework for how we might conceptualise, theorise, identify and study human practices. For the jaded reader - the one who wonders what social scientists have been studying for the past century if not human behaviour, and considers "practice-talk" a hazy and contrived redescription of something wellstudied and entirely familiar - it offers a detailed discussion of the distinctiveness and relative merits of the practice approach as conceived in these pages. To both readers, and to others besides, it offers analysis and illustration of the approach's conceptual, epistemological and methodological implications, and of the specific benefits social scientists and historians might expect to gain from adopting it.

This book thus represents one effort to provide a methodical response to some of the elementary questions raised by David Stern in his survey of the "practical turn" in social theory and the social sciences: 


\section{Introduction}

What is "practice theory"? The best short answer is that it is any theory that treats practice as a fundamental category, or takes practices as its point of departure. Naturally, this answer leads to further questions. What is meant by "practices" here? What is involved in taking practices as a point of departure or a fundamental category, and what does that commitment amount to? And what is the point of the contrast between a practice-based theory and one that starts elsewhere?

(Stern 2003: 185)

These are important questions, and they deserve a clear and reflected response. In answering them, this book aims to promote and contribute to "practice theory" to the lively and burgeoning literature of the past two decades applying an analytical emphasis on practices to the empirical and theoretical study of the social sciences. ${ }^{1}$ But its ambitions are not limited to supplying an application, synthesis or refinement of existing "practice theory", for it aims to strike out in a rather new direction, and to build a coherent and original theory of practices from the ground up. The differences begin already with the first step of the argument, for this book starts from a somewhat idiosyncratic conception of what practices are in the first place. From this point of entry, it constructs an interlocking series of arguments about the basic nature of practices and about the implications of this nature for their effective empirical investigation. Thus, this book hopes to lay certain philosophical, theoretical and methodological foundations for substantive empirical research on the practices of human social life.

The arguments of this book are intended to have a very wide-ranging scope. They suggest that, done well and done carefully, the systematic analysis of historical practices has much to contribute to virtually all substantive realms and topics in the social sciences and humanities. At its best, such analysis will prompt new questions, provide new perspectives, suggest new connections, encourage new conceptualisations of phenomena, stimulate new avenues of research and draw attention to new and previously unnoticed phenomena in social-scientific inquiry. One of the aims of this book is to show, through argument and example, how such broad and diverse consequences might be expected to follow.

\section{A "cultural" approach to social science}

In its emphasis on practices, this book attempts to promote the possibility, power and significance of a broadly "cultural" approach to the social sciences. I do not mean to hang much on the word itself. "Culture" is a vague, multifarious and contested term, and is not one that features prominently in my own work. (Like some anthropologists, I would rather stick to the adjective and typically avoid the nominal form. $)^{2}$ Here I use it instead as a loose, generic and convenient way to refer to a diverse family of approaches to the study of the social world. Speaking very generally, these heterogeneous approaches tend to be variously sensitive, inter alia, to the symbolic, ideological, representational, discursive, practical, ritualistic, identitarian, reflexive, normative, affective, aesthetic, unconscious, 
quotidian, conventional, artefactual, relational, interactional, contextual and constitutive dimensions of social life. (Elsewhere in the book I occasionally make generic reference to "cultural phenomena"; it is elements such as these that are broadly intended.) These approaches are centrally interested, that is, in patterns in the action and in the materially manifest forms of thought of people in particular times and places. ${ }^{3}$

Without denying the significance of other emphases, this book suggests that the relationship between human practices and human knowledge ought to be the analytical centrepiece of "cultural" approaches to the social sciences. Again without dismissing alternatives, it also argues that "cultural" approaches, understood in this sense, are not just one option among others in the social sciences; they are analytically essential to the study of social phenomena in general. It advances a series of arguments in support of this position, along with a detailed investigation of the broad nature and implications of the practice-knowledge relationship.

Many, though not all, "cultural" approaches to social research position themselves outside of the traditional epistemological conventions of the social sciences. ${ }^{4}$ It is customary within the social sciences to group these conventions under the label of "positivism". This label is extremely vague and problematic, and on any careful construal almost certainly false; for familiarity and brevity, on the other hand, it has no going rival. I accept it therefore for the purposes of briefly characterising this book's epistemological stance, which is resolutely non-positivist, indeed probably anti-positivist, in the aforementioned sense of that term. That is to say that it straightforwardly rejects, among other things, the presumed necessity and/or superiority of the hypothetico-deductive model of theory construction and evaluation in the social sciences; the methodological and epistemological unity of the natural and social sciences; the fundamental underlying unity of principles, of inferential standards and of the logic of inquiry in qualitative and quantitative research; the search for "law-like", uniform causal generalisations (whether deterministic or probabilistic in nature); and the understanding of social causality on the broad model - if not necessarily the specific terms - of statistical inference.

There are social scientists who might construe any position that eschews commitments such as these as an intrinsic rejection of "the social-science enterprise". 5 Such claims can only rest on an extremely narrow and arbitrary conception of social science. This book is in part an effort to demonstrate not just the possibility but the great power of a far broader conception of social-scientific inquiry. It is a conception which retains, indeed insists on, a strong commitment to analytical rigour. ${ }^{6}$ In this respect, this book aligns itself with a growing literature in the heterodox social sciences which places a heavy emphasis on conceptual, analytical and methodological issues (e.g. Martin 2011; Hall 1999; Topper 2005; Reed 2011; Packer 2010; Biernacki 2012; Toomela and Valsiner 2010). Rigour of thought and analysis is certainly no proprietary possession of "positivist" social science. Indeed, this book hopes to show that sustained rigorous reflection can demonstrate the profound implausibility - or, at the very least, the wholly optional status of many of the underlying conceptual, ontological, epistemological and methodological assumptions of conventional social-scientific research. An inflexible 
commitment to a particular construal of rigour and a particular image of precision can lead to theorising that is often, in actual fact, neither rigorous nor precise in its characterisation and explanation of the varied phenomena of the social world. It is my aim to develop these reflections and arguments in a clear, systematic and compelling fashion that is accessible to both a mainstream and non-mainstream social-science audience. I also aim to demonstrate in an intuitively plausible fashion what, concretely, is at stake in the issues explored in these pages, particularly for empirical research. I aim, in other words, to show readers exactly why they should care about these issues, whatever their persuasion.

I expect that this book may encounter a different sort of scepticism from certain readers of a more heterodox stripe. These readers may well wonder what the point is, and whether I am not laboriously reinventing the wheel (in an alien and forced analytical vocabulary and style, no less). Some may think this is time wasted resurrecting old, and unproductive, debates; others will believe these debates to have been long settled - in favour of the home team, no doubt. They might also believe that all of my substantive arguments and conclusions are already reflected in existing or current work in social theory and heterodox social science. All of the social-scientific disciplines have had their own pitched epistemological and methodological battles or underground resistance movements; I will not even try to canvas them here. I will leave ultimate judgements about novelty and relevance in the hands of the reader. All I can ask is that the sceptic read the arguments carefully and in full before deciding.

\section{Practice theory today}

This book will directly set out to develop an original account of the nature and significance of practices in the social world. It will not systematically compare this account with the existing literature in practice theory, nor will the existing literature be subject to detailed review and critical assessment. ${ }^{7}$ Nevertheless, it is worth making a few generic points about today's practice theory at the outset in order to highlight some aspects of what is analytically at stake in these pages.

The distinctive character of the account of practices presented here can be traced to its very point of departure: to its conception of what practices are in the first place. In this regard an important point about the understanding of "practice" in the existing literature should be noted. One way of formulating this point might be to observe that practice theorists have typically been interested more in "practice", in the abstract singular and without an article, than in "practices" than in the specific kinds of things that people do and have done, the diverse concrete activities in which they engage. ${ }^{8}$ To date, practice scholars have tended to conceive of practice in terms of habitual or customary performance based on skills acquired through experience, training or routine performance, and embodied in "tacit knowledge" or know-how. ' This conception thus draws in part on the familiar opposition between practice and theory - i.e. rational, reflective, "calculative" thought - drawn in everyday language. Thus practice theorists have stressed the habitual, tacit, non-calculative, non-representational, unspoken and 
"everyday" dimensions of human action. ${ }^{10}$ They have presented practice as a matter of customary or competent activity based on skills acquired through experience, training and routine performance. For these scholars, practice is that broad domain of human action that is familiar to the point where it becomes "second nature" and quasi-automatic, performed without much in the way of deliberate reflection. It is the product of inarticulate skills, practical knowledge and knowhow (not "know-that"), of a "practical sense", a "feel for the game".

Thus in world politics, for instance, the performance of practices of international summitry may be held to rely on often unarticulated and unreflected background knowledge, such as the "very specific and skilful way for state officials to subtly take a little distance from the consensus forged for the official communiqué". Generic practices of strategic bargaining à la Thomas Schelling (1960; 1966) likewise require background skills of effective communication and signalling - of threats, resolve/commitment, correct incentives, etc. - and of being able to walk the fine line between brinkmanship and disaster. Moreover, the communicative practices themselves, as well as their recognition and interpretation, operate almost entirely in the realm of the tacit, given that in the relevant situations, explicit "talk is cheap" (Adler and Pouliot 2011: 7-8). The behaviour of diplomats - e.g. copying budgets, updating protocols, handling a senior promotion - is shaped by their juggling of at least three distinct, often contradictory, unspoken "scripts": those of the bureaucrat, the hero, and the mediator (Neumann 2005). Background tacit knowledge is required for those who witness as much as those who engage in practices. Thus Charles de Gaulle's ostentatious 1963 veto of British membership in the European Common Market reflected a tacit "tradition of great-power lèse-majesté which was quite recognisable even to avowed 'pro-Europeans', much as they may have deplored it" (Navari 2011: 10).

The concerns motivating this approach are important ones. The practice turn has usefully drawn attention to core aspects of human action largely ignored or undertheorised in conventional approaches to social science. These include the "unconscious" and "subconscious", "instinctive", habitual and "corporeal" dimensions of action and knowledge. They also include the variety of capacities and skills which undergird different types of action. Practice theory has drawn attention to the qualitatively distinct nature, the significance and the ubiquity of know-how as a type of knowledge. Sometimes it has been accompanied by renewed attention to people's agency, creativity and active resistance to entrenched, overt forms of order and power. It has contributed to growing attention (in various quarters) to the role of affect and emotion in social behaviour. It has also emphasised the oftneglected "everyday" aspects of social and political life. ${ }^{11}$

There are, however, a number of serious analytical difficulties that afflict explanatory accounts based on such a conception of practice(s). Some of these problems have been set out crisply and incisively by Nigel Pleasants, Theodore Schatzki and Stephen Turner, among others (Pleasants 1996; 1999: chs 4-5; Schatzki 1990; 1997; Turner 1994; 2002: 31-2, 45-7). ${ }^{12}$ (The relative neglect among practice scholars of Schatzki's vigorous arguments against conceptions of practice that appeal to tacit knowledge and tacit rules is particularly striking. 
As an editor of the seminal multidisciplinary volume of practice theory cited in the epigraph, and author of three of the only book-length practice accounts to date, his is one name known to all advocates of the practice turn in the social sciences and humanities.)

One key issue is the explanatory ambition of these accounts. It may be that identifying, conceptualising and characterising action and behaviour come across as fairly uninteresting, and largely atheoretical, exercises - preliminaries, perhaps, to social-scientific investigation, and not ends in themselves. Even scholars who eschew mainstream epistemic practices may nonetheless share a widespread, if perhaps largely unconscious, assumption in the social sciences: that as social phenomena, action and behaviour are more or less uncomplicated and straightforward to identify, describe and classify - unlike, perhaps, motives, intentions, ideas, norms, culture, discourse, functions, structures, institutions and so on. (That such an assumption may cross epistemological lines might help explain why a social-scientific focus on "mere" behavioural regularities seems to strike so many "non-positivist" scholars as narrow and analytically regressive.) $)^{13}$ Challenging this assumption is one aim of this book. The book thus stresses the profound importance and interest, but also the profound complexity, of effectively characterising human behaviour for social-scientific research. My personal sense is that there is little that is straightforward about identifying generic forms of human behaviour for the purposes of general explanation. This applies even to those forms of behaviour we are inclined to find extremely familiar.

Whatever the reasons, there is a clear pattern in the practice turn. To this point, specific empirical practices, and their particular features and interrelations, have not been the object of primary theoretical interest. When they do receive attention, it is typically derivative. They are examined because, and to the extent that, these activities are thought to exhibit features held to be typical of "practice" in general - for instance, a certain tacit, unreflective, intuitive, skilful, nonrepresentational, commonsensical or habitual quality. These shared qualities, and not the specific details of the specific activities (in and of) themselves, are the main object of attention. Moreover, what is supposed to be theoretically interesting about these practices is that they embody, or are symptoms of, certain other types of phenomena which are held to underlie and to structure, guide and produce them: dispositions, tacit knowledge, tacit (or constitutive) rules, norms, principles, codes, formulae, habits, habitus, conventions, standards of correctness, attitudes, scripts, schemes, cognitive schemata, and so forth. ${ }^{14}$

The result is somewhat ironic for an approach that purports to privilege practice. Practice scholars have often done little to systematically identify and theorise, with close precision, the actual activities of social life themselves. For much of this work "practices" has, in a sense, functioned as an odd placeholder term. Use of the concept is supposed to signal a certain interest in materiality as against, typically, the alleged non-materiality of discourse and texts. Yet in practice, scholarship citing it tends to remark only incidentally or in an ad hoc fashion on the concrete things people actually do. The real theoretical attention is in fact devoted to those entities which are alleged to cause (or "constitute") 
and explain people's actions. Sometimes the terms "practice" and "practices" are actually used to refer to these underlying phenomena, ${ }^{15}$ and not the activities they supposedly produce. Other scholars seem to slide arbitrarily between the one and the other when referring to "practices".

I will not engage in a systematic critique of existing practice theory here. These problematic features aren't at any rate unique to it; they are characteristic of the treatment of the "cultural" realm in the social sciences more generally. Two in particular may be noted. One concerns the way the explanatory relationship between action and the proposed underlying cultural phenomenon is conceived. This relationship is seen either as an instance of garden-variety causality, or, more intriguingly, as a "constitutive" relation. The former view is simplistic, unrealistic and exceedingly narrow. The latter is more promising, but typically left extremely vague and undertheorised by its advocates. On those rare occasions that it is given flesh, it very often turns out to be construed as a softer form of determination in social life than causality, a kind of "causality-lite". Its broad epistemic aims and form are similar to those of traditional causal explanation of human behaviour: to account for the occurrence of specific actions on specific occasions. In this book, I argue that this is the wrong thing to ask of "cultural" theories of the social world. In Chapter 7, I endorse the appeal to constitutive relations, but argue that these should be conceptualised in a rather distinctive fashion.

The other aspect common to these approaches to practice - and to "cultural" accounts more broadly - is the nature of the "explanans", the cultural phenomena alleged to do the explaining. Examples include (tacit) rules, norms, principles, dispositions, tacit knowledge, habits, habitus, conventions, scripts, hexis, standards, codes, (unspoken) formulae, attitudes, schemes, schemata and tendencies. Each of these has a venerable pedigree in the social sciences. And despite non-trivial differences among them, they form something of a family. They all represent hidden entities that are supposed to exist in addition to, to underlie, and to infuse and generate the manifest actions they are cited to explain.

Though some of them have certain limited uses, I consider them generally to be rather suspect and occult analytical objects. In most cases one can reasonably doubt whether any coherent entities corresponding to these categories actually exist. One can also question the explanatory logic and power of such entities, and indeed argue that there is little to nothing that positing such entities adds to a careful description of the activities themselves. Just as corrosively, a powerful case can be made that not only are allegedly ubiquitous objects like tacit social rules, norms and behavioural dispositions not needed to make sense of human behaviour, but that they could not fulfil this role even if they were. What's more, one might plausibly argue that the analytical dependence actually runs in the opposite direction from the one imagined: that the identification and characterisation of "norms", "dispositions" and "tacit rules" that allegedly explain practices, and the impression of their explanatory power, fundamentally rely on the theorist's prior grasp of features of the practices themselves - and, at their most effective, often simply restate or redescribe those features. In the place of pseudo-explainers like these, I will recommend sustained attention to that very behaviour, to the actual 
practices themselves, as well as to their constitutive relationship with knowledge in its material and discursive forms. A close examination of concrete practices and knowledge will help produce not only more accurate and useful description, conceptualisation and characterisation but also more successful (constitutive and even causal) explanation.

\section{Core ontological commitments}

Together, the arguments advanced in this book urge a particular image of socialscientific inquiry, based upon what it takes to be core features of the ontology of the social world. A few very general and abstract aspects of this image can be specified at the outset. One is the ineliminably historical nature of the social world and of the phenomena therein. Practices are fundamentally historical phenomena, which come into being, exist and disappear in a particular time and place. Our epistemic practices - particularly our practices of conceptualising, characterising and generalising about social phenomena - should therefore be oriented to, and genuinely reflect, this historicity. Second, and relatedly, practices are contingent phenomena. There are few human practices of any moderate complexity that are universal in any meaningful sense, and what might at first appear to be subtle or minor differences between practices can be of considerable significance for social-scientific inquiry. Most human practices did not, strictly speaking, have to arise at all or take the form they did; most have required specific conditions for their existence, and have depended profoundly on elements of their historical context for their very nature and persistence.

A third point follows from this: that human practices, and therefore virtually all social phenomena, are deeply contextual things. They are in important part constituted by specific elements of their context, and cannot be fully identified and understood in analytic isolation from that context. This leads to a fourth point: if contexts are fundamental to the very identity and existence of practices (and other social phenomena), then we need to identify them with far greater specificity than they have hitherto been. We should proliferate the number of social phenomena we recognise, and seek to identify and distinguish them in their cultural and historical specificity. This has direct implications for social-scientific conceptformation. In particular, the kinds of abstract, typologically oriented, functional concepts typical of conventional social science will normally be profoundly inadequate to the (contextually varied) phenomena they seek to capture and describe. Thence, too, a fifth point: the relationship between a practice and the key elements of its context is constitutive in nature. This constitutive relationship helps us to understand not only the existence but the specific features and indeed the very generality of a practice. Many of the central sorts of explanatory generalisations to be made about practices will therefore be generalisations about constitutive relations and can best, perhaps only, be captured by constitutive theorising.

Yet this is not to deny the role, presence or indeed ubiquity of causality in the social world. Many heterodox approaches to the social sciences have tended to reject outright the relevance or even the possibility of causal inquiry into the 
social world. Others have accepted something of an intellectual division of labour, effectively leaving causal inquiry to the "positivists". Though I understand the impulse behind the first response, and indeed once felt it myself, I believe both to be mistaken. What is fundamentally problematic, I believe, is not the existence, extent or importance of social causality, but the particular monolithic conception of causality presumed by mainstream social-scientific inquiry. Countless variants of this conception have been offered, but its core is remarkably stable, and it is so widespread and so deeply entrenched, in our daily lives as much as in academic research, that it has effectively become synonymous with causality tout court. It is something along the lines of the motivating image behind statistical inference: what might be called "correlation-plus" - uniformly regular covariance of the occurrence of instances (or of the "values" of some attribute) of the explanans and explanandum, plus some mysterious "extra" element, its identity endlessly debated, that secures actual causal influence from the one to the other. The covariance may be deterministic or stochastic in nature, but either way, it is uniform in its regularity.

In my view, this conception is fundamentally inappropriate as a characterisation of virtually any actually existing form of social causality. It is fine, indeed quite useful, to speak of causes and causings in the social world, so long as we drop the assumption of uniform regularity and attend to the possibility of plural and perhaps extremely diverse forms of social causality. In Chapter 6 we will see one proposal for a generic way of characterising this irregularity and this potential diversity. In Chapters 6 and 7, I present arguments that attempt to reconcile the simultaneous possibility in the social world of vast causal diversity and contingency, on the one hand, and the manifest regularity and generality of social phenomena, on the other. Again, these arguments underscore the significance and autonomy of constitutive theory.

A final word on pigeonholes, "-isms" and tribal allegiances. I am somewhat wary of labels. No doubt they are necessary to some extent. On the other hand, they too often function as shortcuts and indeed substitutes for critical thought. They can allow scholars, particularly when confronted with the unfamiliar, to peg and to typecast, and to trot out glib stock criticisms, without feeling any need for careful engagement with arguments. Despite the diverse range of theoretical approaches and philosophical positions on offer in the social sciences today, I'm not sure that this work fits very easily into any of them. One can't realistically expect, however, to escape assignment to more familiar categories. A little preemptive self-identification, then, for whatever it's worth.

Philosophically, this book is strongly influenced by the work of the so-called Stanford School in the history/philosophy of science. For a period during the 1980s, the Stanford philosophy department was home to a formidable group of broadly like-minded thinkers: Ian Hacking, Nancy Cartwright, John Dupré, Peter Galison, Margaret Morrison and Arnold Davidson. The subject matter of this book reflects one of their primary philosophical preoccupations: "One thing that unites Stanford School practitioners is a strong respect for scientific practice actual scientific practice" (Hoefer 2008: 1; original emphasis). The names and 